\title{
SEISMIC ANALYSIS OF BRIDGE BEARINGS USING DIFFERENT SHEAR MODULUS
}

\author{
M. M. Husain and Heba A. Mohamed \\ Structural Engineering Department, Faculty of Engineering, \\ Zagazig University, Zagazig 44519, Egypt.
}

Ayman M. Aboraya

Construction and Building Department, The Higher Institute of Engineering, October 6th city 12592, Egypt.

\begin{abstract}
Throughout seismic actions, several factors affect the behavior of RC bridges. The shear modulus of the elastomeric bearings pads is one of these most important factors. Elastomeric bearing pads are usually existed at the ends of the bridge superstructures to act as rigid constraints. The support boundary condition is defined by bearing pads and its existence can affect the seismic behavior of bridges. During this research, AASHTO design standards are used throughout this work. The bridges in this research were selected from actually executed in the Arab Republic of Egypt, according to the Egyptian code of practice [ECP, 2007], and located in the third seismic zone. The applied element method [AEM] is used to analyses the bridge models in this research the effect of changing the shear modulus of the bearing pads on the seismic behavior of RC T-Girder bridges is studied under a sever ground motion like Chi-Chi. The behavior of changing the bridge configuration is also studied. The research results showed that the seismic behavior of RC bridges it is highly affected by the value of shear modulus of the bearing pads and the existence of the bearing pads can isolate the seismic energy from the columns till failure.
\end{abstract}

Keywords: Seismic Analysis; Method of Applied Element; Bridge Bearing plates; Reinforced Concrete; Numerical Analysis

Cite this Article: M. M. Husain, Heba A. Mohamed and Ayman M. Aboraya, Seismic Analysis of Bridge Bearings using Different Shear Modulus, International Journal of Civil Engineering and Technology, 11(5), 2020, pp. 181-191.

https://iaeme.com/Home/issue/IJCIET?Volume=11\&Issue=5

\section{INTRODUCTION}

Strong earthquakes produce sizeable amounts of energy into structures and may cause the structures to deform excessively or even collapse. For durable structures, they must have the ability to dissipate this incoming energy either through their internal damping mechanism or through inelastic deformation. This energy dissipation matter is becoming even more intense for bridge structures, particularly bridges with a long-span, which have very low inherent 
damping. When strong earthquake motions affect these structures, excessive deformations will produced by relying on solely inelastic deformation and inherent damping. Excessive deformation may lead to serious degradation or even collapse for bridge structures that designed mainly on service and gravity loads.

Numerous studies have carried out on modeling and analysis the behavior of bridge structures (Yazdani et al., 2000, Dicleli Buddaram, 2006, Jangid, 2002, and Dai et al, 2005). Such studies have made a significant contribution in various ways to the current research. Especially, in investigation and discussion of the effect of modeling parameters. Elastic and non-linear analysis factors are covered in this regard, Aiken and Kikuchi (1996) offered an analytical hysteresis model for elastomeric seismic insulation bearings. However, minimal researchers have concentrated on the behavior of typical elastomeric pads which are not known as isolation bearings. Elastomeric bearing plates were used to support both ends of Tgirders bridges. The interface of the bearing pad-bridge girder determines the boundary conditions of the support and may influence the seismic behavior of the bridge. This study mainly focuses on the effect of changing the shear modulus of the bearing interface on the behavior of RC T-girder Bridge under Chi-Chi ground motion.

\section{APPLIED ELEMENT METHOD}

Based on the AEM, The Extreme Loading for Structures (ELS) program is a new generation of analytical programs to solve 3D problems is presented by Tagel-Din and Meguro (2000a, b). AEM is an innovative simulation approach that depends on the discrete cracking approach, Fig.1. Structures are built up as an assembly of the elements. Shear and normal springs were used to link the element surfaces. Stresses of Normal and shear, between the neighboring elements, are transferred by such springs. Sole spring denotes a specific volume of material's stresses and deformations, Fig. 1. When the connecting springs fail, each of the two adjacent elements willfully separated. The ELS go through a fully nonlinear path-dependent material constitutive models, Fig. 1. AEM is a stiffness-based method that an overall matrix of stiffness and equilibrium equations are constructed for each of the stiffnesses. The deformations are gotten by solving the damping and mass matrices nonlinearly. The method for equilibrium equation is an implicit one that requires dynamic integration step by step (Newmark-beta time integration procedure). (Chopra; Bathe 1995). If the springs joining the elements failed, they are separated from the other. Neighboring elements may separate, recontact or contact other elements depending on the of the response structure, Fig. 2.
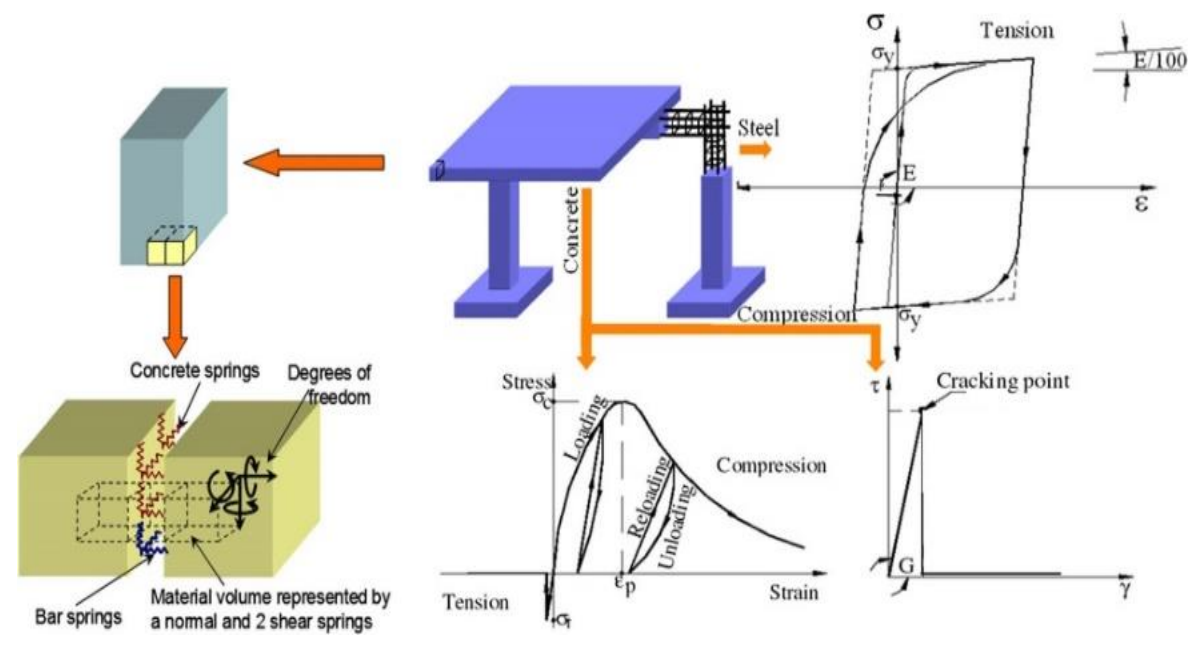

Figure 1 Structural Modeling According to AEM Salem, et al. (2016). 


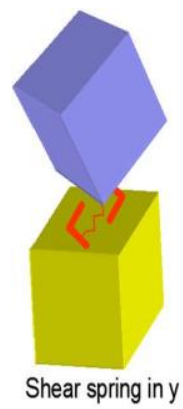

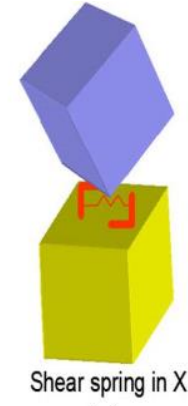

(a)
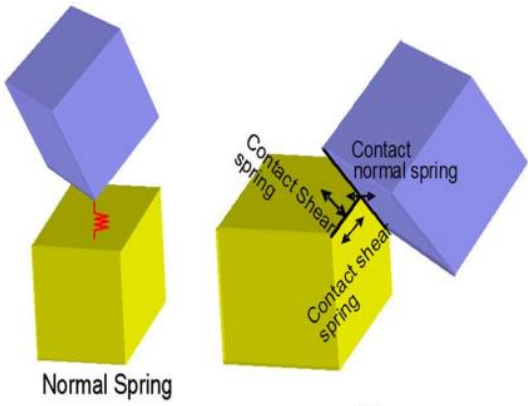

(b)

Figure 2 Types of contacts between elements: (a) corner to face, corner to ground contact, and (b) edge to edge contact, Salem, et al. (2016).

\section{MATERIAL MODELS}

\subsection{Modeling Concrete and Reinforcing Steel}

For concrete, the Elasto-Plastic and fracture models in compression, was introduced by Okamura and Maekawa in 1983. The linear tension stress-strain relationship is introduced as the concrete is bare to tension until cracking then the stresses are set to zero after that. As AEM follow the discrete crack approach, tension bars are used to represent the reinforcing bars.

\subsection{Bridge Bearing Material}

The elastomeric bearing pad is defined by an interface material. The model of the interface material is a pre-cracked element. For tension, the material model is originally cracked and won't withstand any tensile stresses. While for compression, the stress-strain curve is assumed linear until the stress value of compression reaches the fracture value, Fig.3. For shear, stress and strain relation is linear until the shear stress reaches $\mu \sigma_{\mathrm{n}}$ (coefficient of normal friction product by normal stress). At the stress level, providing that the normal stresses are constant, the shear stress remains $\mu \sigma_{\mathrm{n}}$. Further increase in the compressive stresses increases the shear stresses. Once the crack is opened or during sliding the shear stress will exceed $\mu \sigma_{\mathrm{n}}$. Then shear stiffness is set to the lowest value, Fig3, Salem et al (2016).

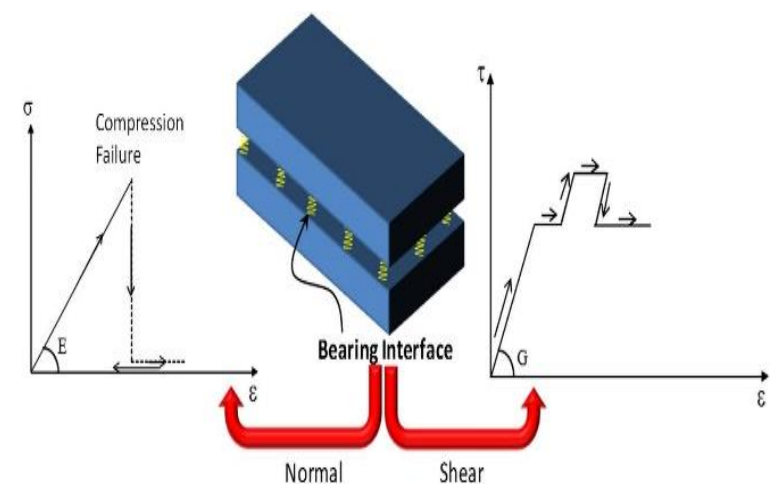

Figure 3 Bearing Interface According to AEM; Salem, et Al. (2016).

\section{BRIDGE MODELS}

\subsection{Bridge Layout}

The RC T-Girder Bridge has a span of $25 \mathrm{~ms}$. Two bridge systems were studied, the first is that the superstructures are simply supported on a bearing plates from both ends. The second bridge system is that the bridge superstructure is monolithic with the bridge piers. The bridge 
piers have $6.65 \mathrm{~ms}$ height. The columns were assumed fixed at the pier's bases. The superstructure of the bridge is supported on elastomeric bearing pads. Five elastomeric pads are put in each bearing row. The reinforcement details and bridge dimensions and were obtained from an executed multi-span T-girder bridge located in Egypt that is designed to conform to the ECP, 2007, Fig.5. A 5\% damping ratio was assumed in the study. The analyzed bridge models and amount of reinforcement of the T-girders are offered in Table 1. The aim of this study to find the effect of change in the shear modulus of the bearing plates on the seismic response of the bridge piers under extreme seismic ground motion, as in Chi-Chi.

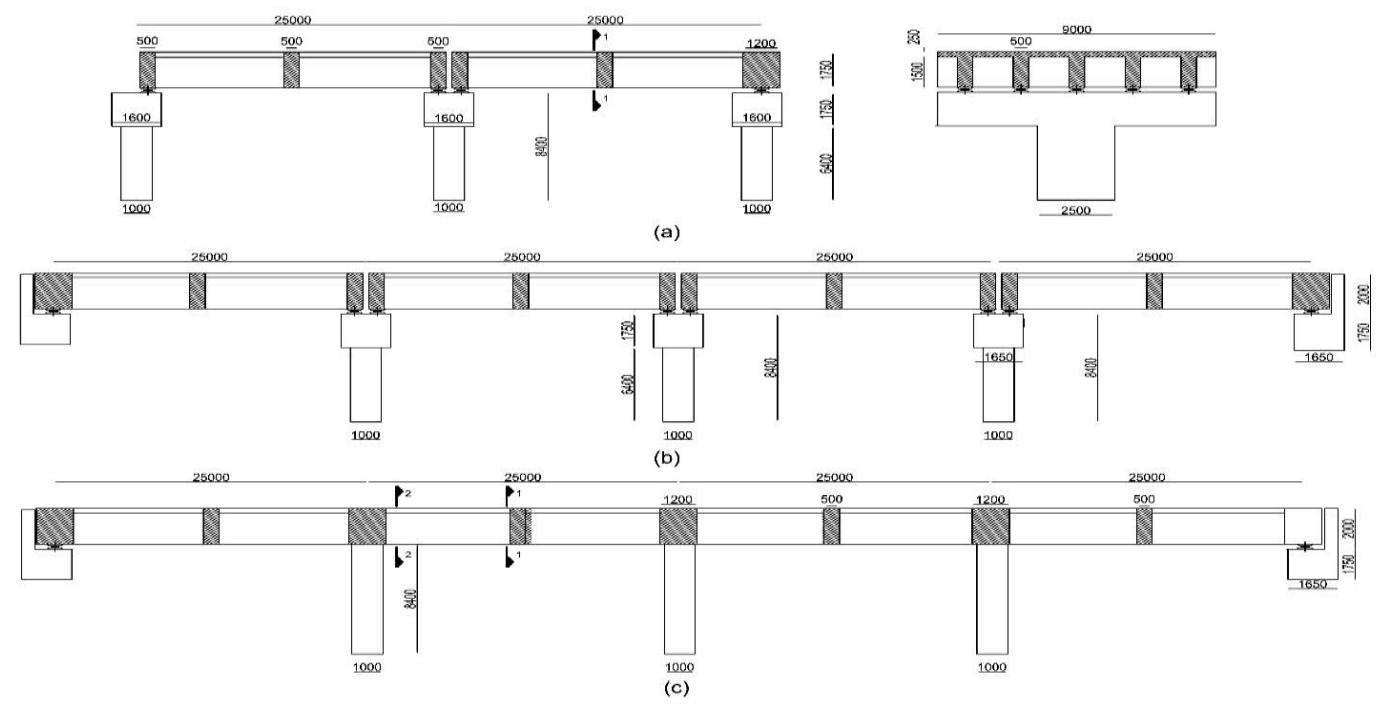

Figure 4 T-girder bridge models: (a) Simple on bearings; (b) Continuous on bearing ; (c) Monolithic with columns T-girder bridges

\subsection{Material Properties}

The properties of the materials used in the AEM are presented in Table 2.The bearing plates used during the analysis consisted of upper and lower steel plates and a bearing material between them. The used steel plate's dimensions are 50x50x5 cm. The elastomeric bearing interface dimension is assumed $35 \times 35 \times 13 \mathrm{~cm}$. The property of a bearing material has been used to define the bearing interface between the steel plates. The bearing interface has given a relatively high compressive strength in order not to fail in compression and acts linearly (Chen, W. F., 2014; Akogul, C, 2008; Aria, M., 2013; Salem, H., 2016).
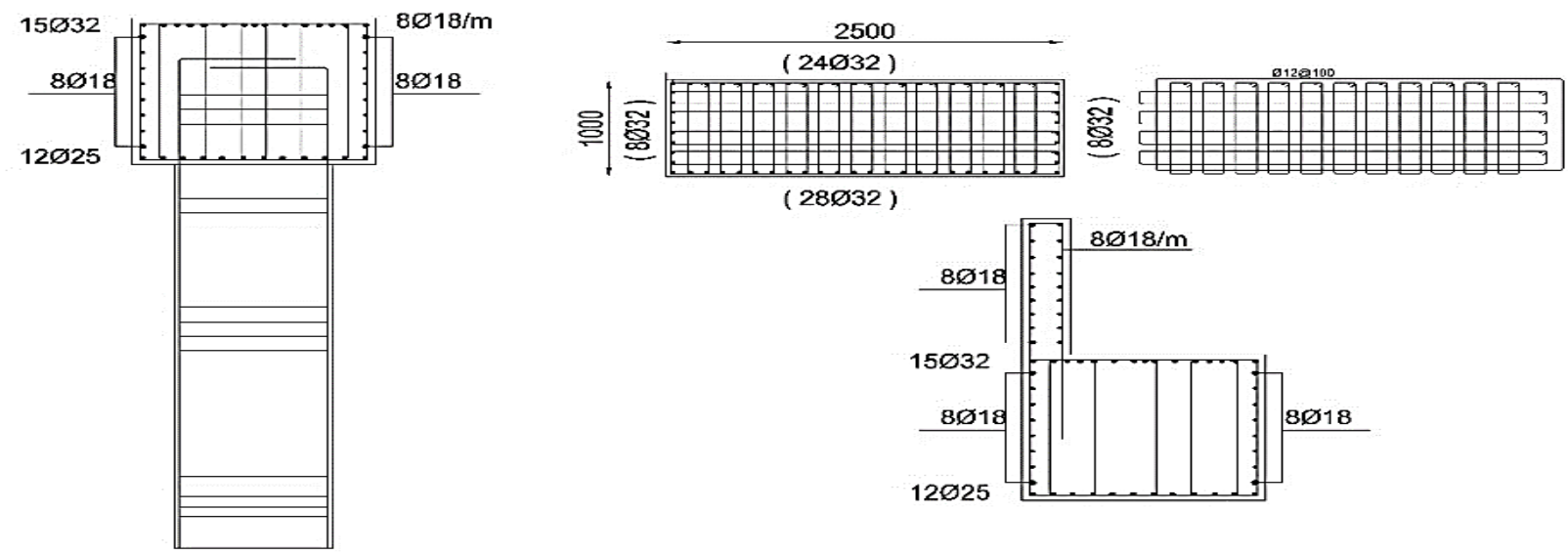

Figure 5 Reinforcement details of the bridge elements. 
M. M. Husain, Heba A. Mohamed and Ayman M. Aboraya

Table 1 Bridge models and T-girder reinforcements (unit: $\mathrm{mm}$ ).

\begin{tabular}{|c|c|c|c|c|c|c|c|c|}
\hline \multirow[t]{2}{*}{ Model } & \multirow{2}{*}{$\begin{array}{l}\text { Bridge } \\
\text { System }\end{array}$} & \multirow{2}{*}{$\begin{array}{l}\text { Bearing } \\
\text { Shear } \\
\text { modulus } \\
\text { (Mpa) }\end{array}$} & \multirow[t]{2}{*}{ Section } & \multicolumn{4}{|c|}{ Reinforcement of the T-girder } & \multirow{2}{*}{$\begin{array}{c}\begin{array}{c}\text { Reinforcement } \\
\text { of the Deck } \\
\text { Slab }\end{array} \\
\begin{array}{c}\text { Top \& Bot } \\
\text { Rft. }\end{array}\end{array}$} \\
\hline & & & & Bottom & Top & Stirrups & $\begin{array}{c}\text { Shrinkage } \\
\text { bars }\end{array}$ & \\
\hline S-B-2 & Simple & 2 & 1 & $20 \emptyset 32$ & $6 \emptyset 22$ & $6 \emptyset 12$ & Ø16@300 & 16Ø@140 \\
\hline S-B-20 & Simple & 20 & 1 & $20 \varnothing 32$ & $6 \emptyset 22$ & $6 \varnothing 12$ & Ø16@300 & 16Ø@140 \\
\hline S-B-200 & Simple & 200 & 1 & $20 \varnothing 32$ & $6 \varnothing 22$ & & 16@300 & 16Ø@140 \\
\hline \multirow{2}{*}{ C-B-2 } & \multirow{2}{*}{ Continuous } & & 1 & $12 \emptyset 32$ & $6 \varnothing 22$ & $6 \emptyset 12$ & Ø16@3 & 16Ø@140 \\
\hline & & & 2 & $12 \emptyset 32$ & $20 \varnothing 28$ & $6 \varnothing 12$ & Ø16@300 & 16Ø@140 \\
\hline \multirow{2}{*}{ M-B-2 } & \multirow{2}{*}{ Monolithic } & \multirow[b]{2}{*}{2} & 1 & $12 \emptyset 32$ & $6 \emptyset 22$ & $6 \emptyset 12$ & Ø16@300 & 16Ø@140 \\
\hline & & & 2 & $12 \varnothing 32$ & $20 \varnothing 28$ & $6 \varnothing 12$ & Ø16@300 & 16Ø@140 \\
\hline
\end{tabular}

\section{GROUND ACCELERATION}

Chi-Chi ground Acceleration is gotten from Strong Motion Database, the Pacific Earthquake Engineering Research (PEER, 2019). The earthquake record in this study is the September 20, 1999 Chi-Chi earthquake record obtained from the Central Weather Bureau (CWB) Taiwan Station CHY028 with site condition classified as class $\mathrm{C}$ according to USGS. This earthquake has a moment magnitude of 7.6. The peak ground acceleration for $\mathrm{x}$-direction is $0.63 \mathrm{~g}$. The time used in the seismic study has been shortened to the time that includes the highest amplitudes of seismic acceleration, as the time that does not contain significant acceleration values has been removed. The total time used during the analysis was 15 seconds. The time history record for this earthquake is shown in Fig. 6.

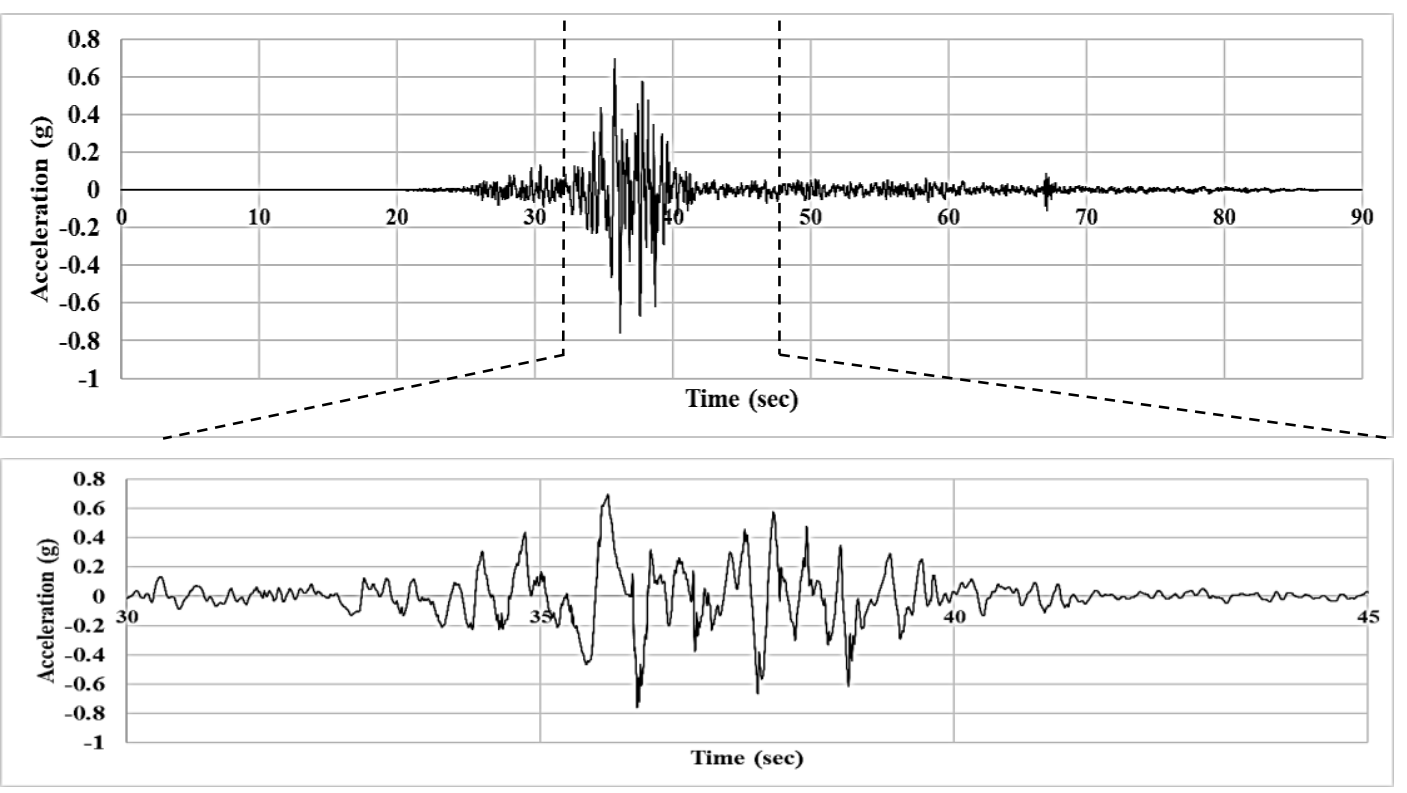

Figure 6 Chi-Chi seismic ground motion, (PEER, 2019).

\section{MESHING FINESSE OF THE BRIDGE ELEMENTS}

A mesh finesse analysis was performed out to find the appropriate mesh number to be used in the analysis of the bridge models. For the displacement and the deflection of the piers and Tgirders, a horizontal and a vertical concentrated load were used respectively. Fig.7 displays the relation between the mesh finesse, and the column displacement and the deflection of the T-girder. It was noticed that a number of 1320 and 1900 mesh elements is sufficient to 
converge the values of displacement and deformations. A total of 7500, 14500, and 11350 elements were used for the simple, and continuous, and monolithic bridges, respectively.
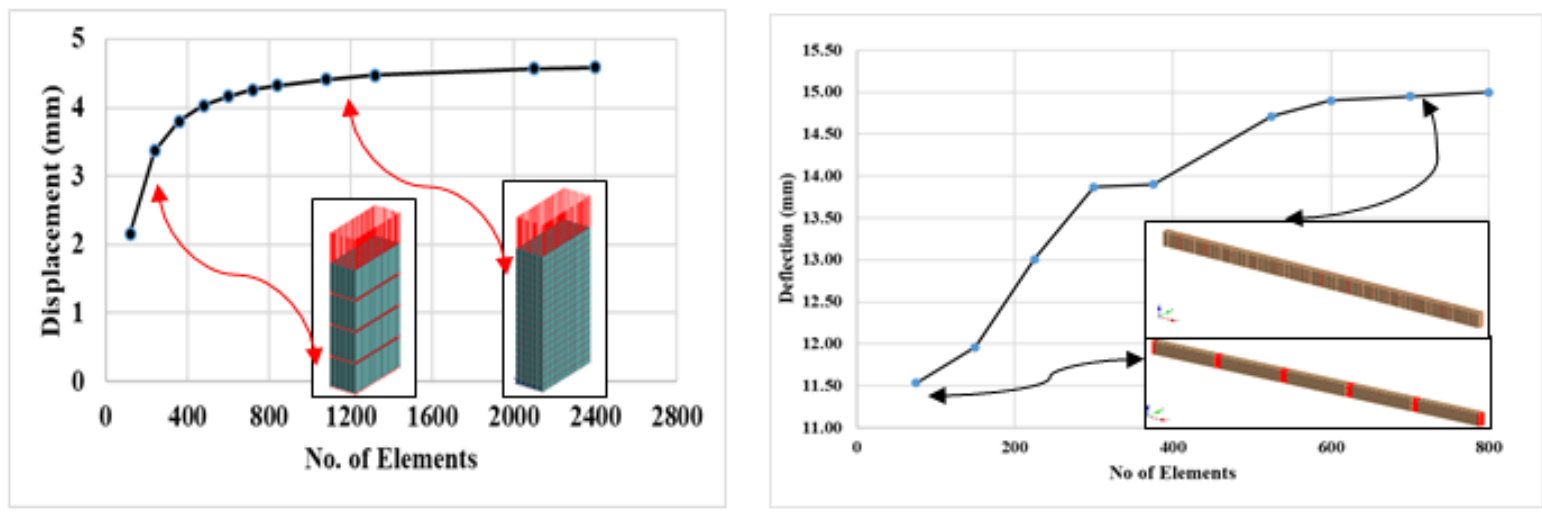

Figure 7 Mesh Finesse of the column, and the T-girder.

\section{ANALYSIS RESULTS}

\subsection{Effect of Changing the Shear Modulus of the Bearing Plate}

Figure 8 to 10 shows the Displacement-Time history of the bridge columns and the Superstructure of the different bridge models with different shear modulus, the middle pier and the bridge superstructure of models S-B-2 and S-B-20 didn't show any significant displacement during the first 4 seconds due to low shear modulus of the bearing plates. On the other hand, due to increasing the shear modulus in model S-B-200, the middle pier and the bridge superstructure began to displace from the beginning of the time history. It is also noted that in low shear modulus, the bearing plate act as an isolator between the bridge pier and superstructure which make the pier vibrates with a wave that is different from those of the bridge superstructure. Once the bearing plate fails, the pier and the superstructure will vibrate with the same wave till the end of the analysis. While using a very stiff bearing plate, as in model S-B-200, will make the pier and the superstructure vibrate with the same wave and the amplitude from the beginning of the time history.

Fig.11 shows a comparison between the displacement time history of the middle pier of models S-B-2, S-B-20, and S-B-200. At the $6^{\text {th }}$ second, the amplitude heights of displacement equals $425 \mathrm{~mm}, 325 \mathrm{~mm}$, and $270 \mathrm{~mm}$ respectively. It can be concluded that by increasing the shear modulus of the bridge pier, the displacement amplitude can be reduced. While reducing the shear modulus of the bearing plate prevent the resonance at the beginning of the time history.

Fig.12 to 14, shows the principal strain of the bearing plate of models B-S-2, B-S-20, and B-S-200 which express the failure shape of the bearing plates. The bearing plate of models $\mathrm{S}$ B2, and S-B-20 failed at $4.4 \mathrm{sec}$ and $6.6 \mathrm{sec}$ respectively. While as a result of high shear modulus in model S-B-200, the bearing plate didn`t fail to the end of the time history. 
M. M. Husain, Heba A. Mohamed and Ayman M. Aboraya

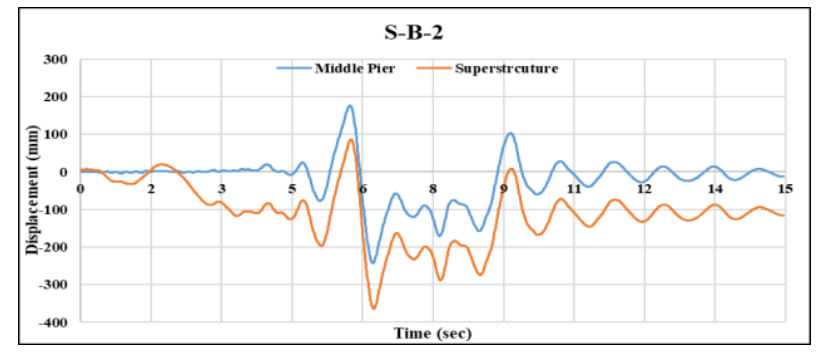

Figure 8 Displacement-Time History of Model S-B-2

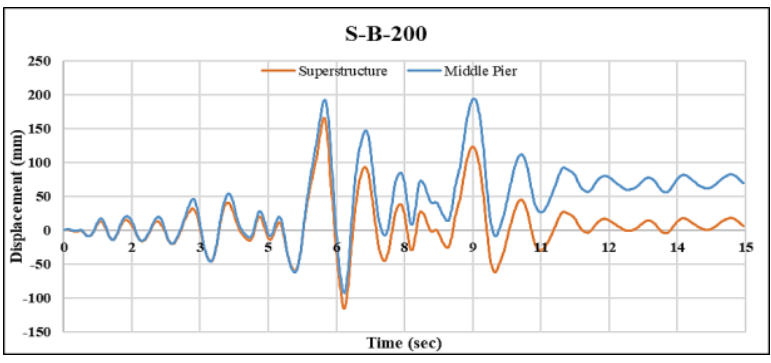

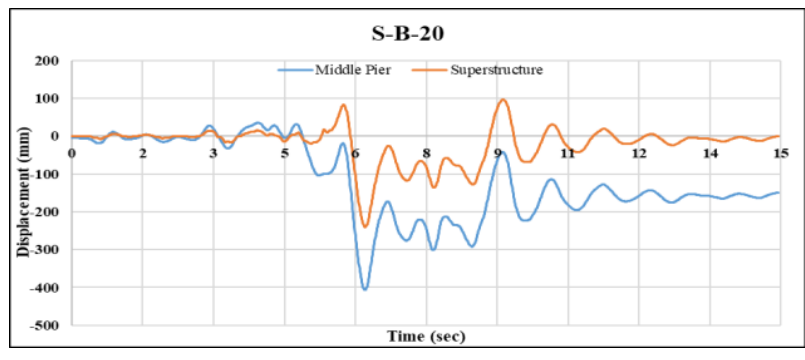

Figure 9 Displacement-Time History of Model S-B-20

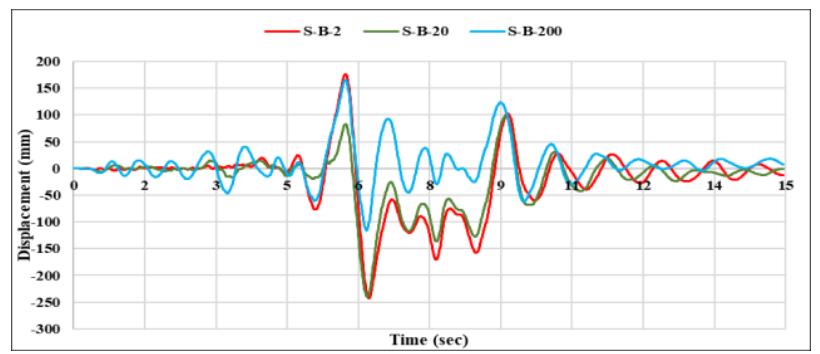

Figure 10 Displacement-Time History of Model S-B-200 Figure 11 Displacement-Time History of the Middle Pier of Models S-B-2, S-B-20, and S-B-200
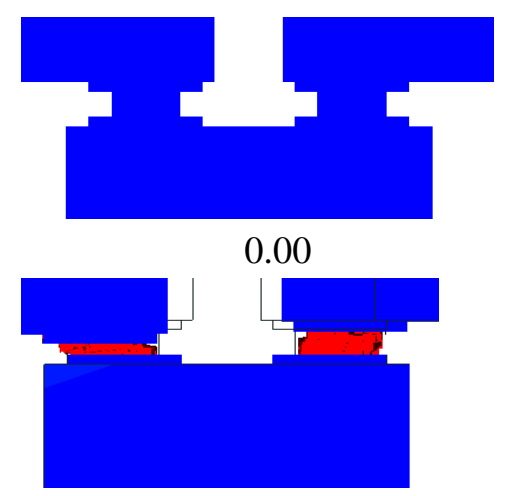

$4.15 \mathrm{sec}$

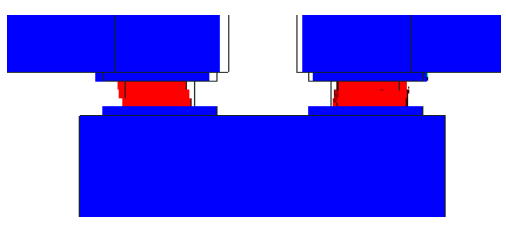

$2.3 \mathrm{sec}$

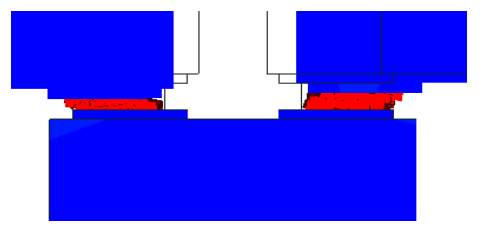

$4.25 \mathrm{sec}$

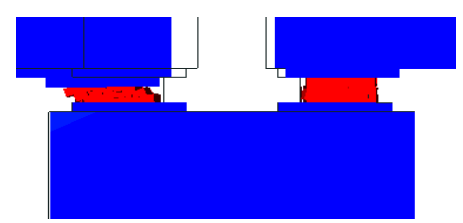

$3.25 \mathrm{sec}$

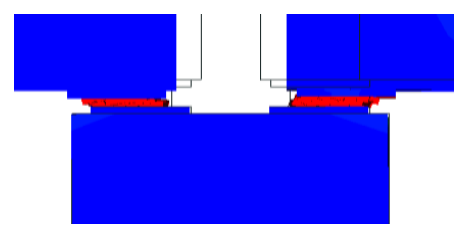

$4.40 \mathrm{sec}$

Figure 12 Principal strain of Bearings of model S-B-2

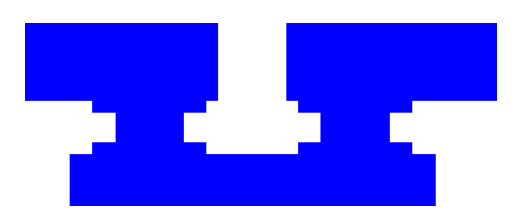

0.00

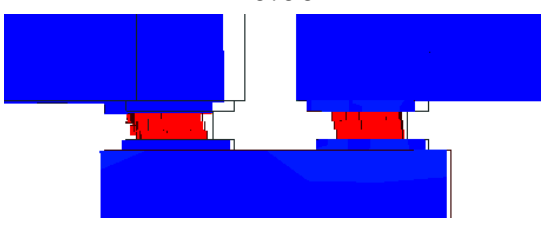

$5.05 \mathrm{sec}$

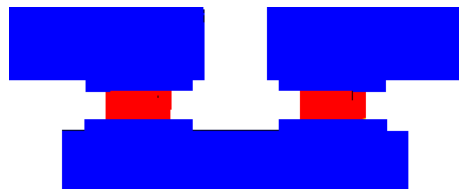

$2.3 \mathrm{sec}$

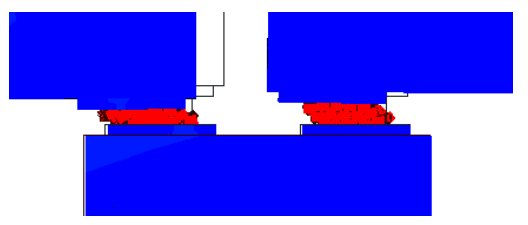

$5.40 \mathrm{sec}$

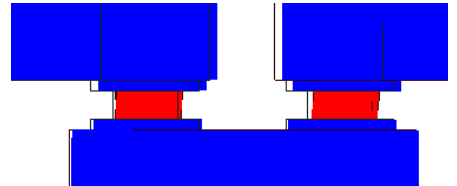

$4.00 \mathrm{sec}$

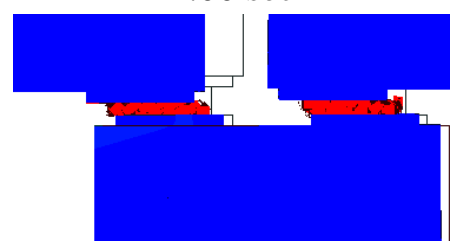

$6.60 \mathrm{sec}$

Figure 13 Principal strain of Bearings of model S-B-20 


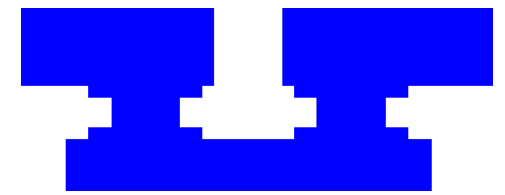

0.00

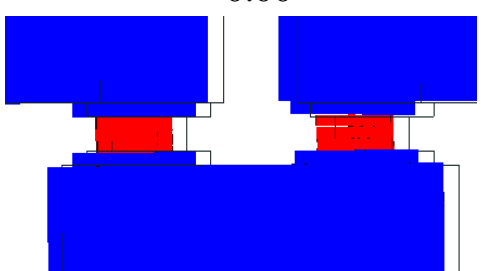

$5.05 \mathrm{sec}$

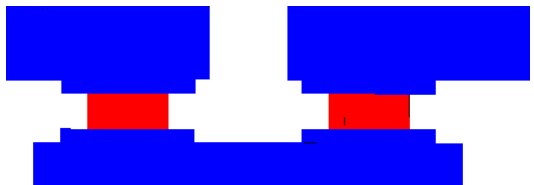

$2.3 \mathrm{sec}$

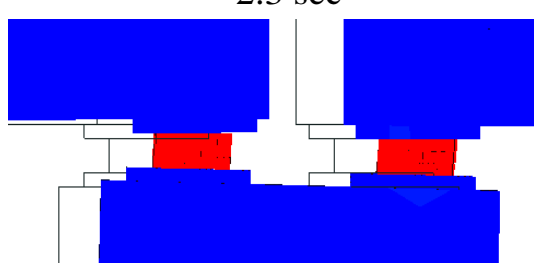

$5.40 \mathrm{sec}$

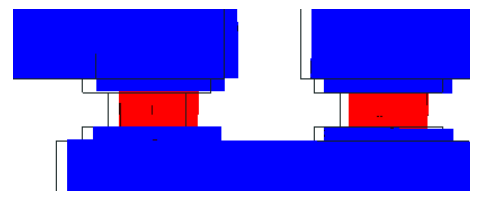

$4.00 \mathrm{sec}$

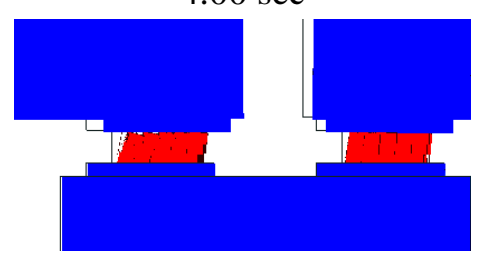

$15.00 \mathrm{sec}$

Figure 14 Principal strain of Bearings of model S-B-200

Fig. 15 shows the principal strain of the bridge models S-B-2, S-B-20, S-B-200 at the end of the analysis respectively. It can be noted that, the exterior column always shows cracks at the bottom end near the base. By increasing the shear modulus, the cracks increases. The Axial load-Time History is shown in fig.16, As a result of the low shear modulus, curves S-B2 , and S-B-20 shows an irregular cyclic reversal waves of motion. Once a rupture of the bearing occurs, the time history begins to show uniformity in the cyclic reversal waves of motion. The rupture of the bearing is also noted between the second and fifth seconds for models S-B-2, while it is also noted in model S-B-20 forth to the sixth second. On the other hand, high shear modulus shows a uniform cyclic reversal waves of motion as the bearing plates are very stiff and didn`t collapse during the time history.

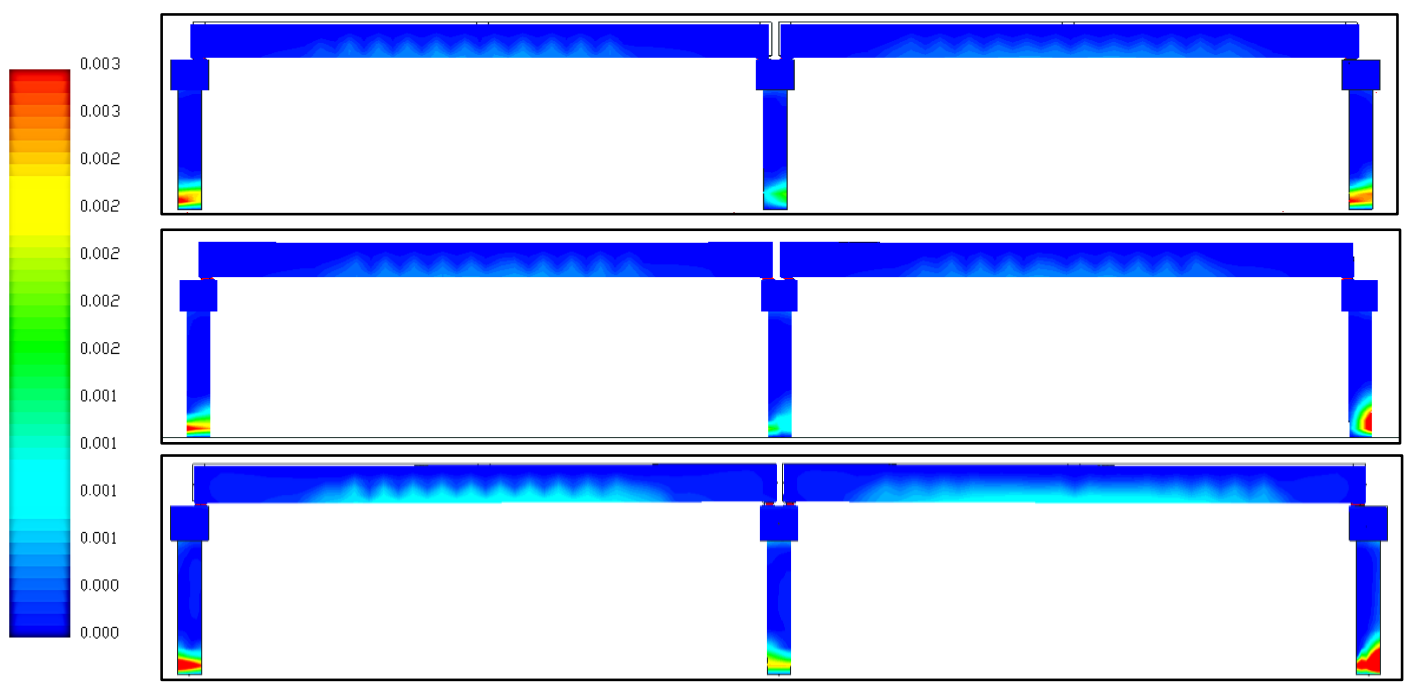

(a)

(b)

Figure 15. Principal Strain: (a) S-B-2; (b) S-B-20 ; (c) S-B-200 models

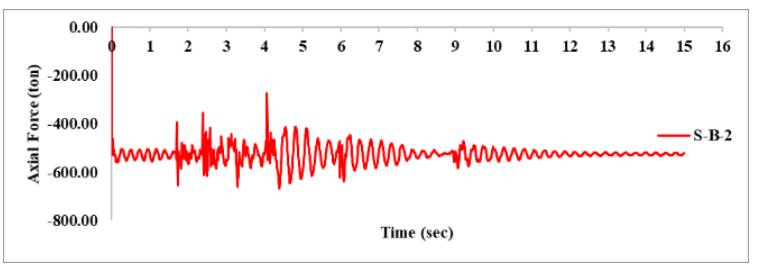




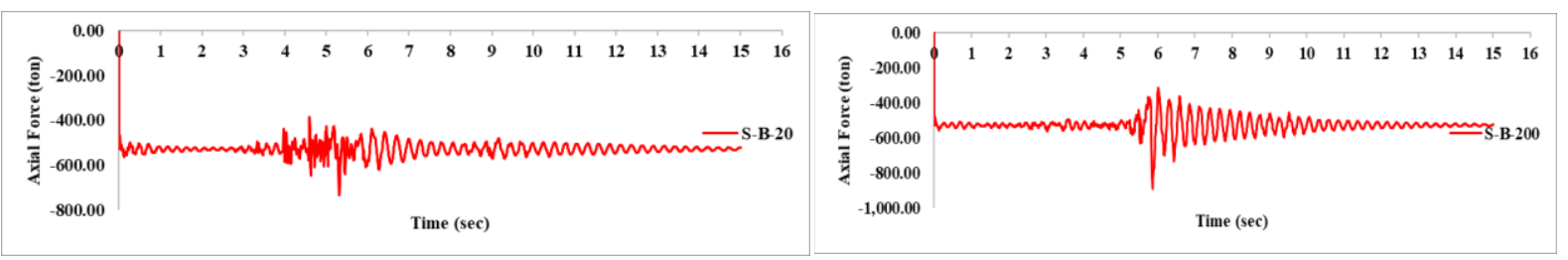

Figure 16. Axial Force-Time History: (a) S-B-2; (b) S-B-20; and (c) S-B-200

\subsection{Effect of Changing the Bridge Structural System}

Fig.17 shows the displacement time history of models S-B-2, C-B-2, and M-B-2. The difference between these bridge models is the bridge configuration with the bearing plates. In the first five seconds, it is noted that the monolithic bridge has a significant resonance as a result of the nonexistence of the bearing plates between the bridge pier and the superstructure. While the resonance of S-B-2, and C-B-2 nearly equal zero due to the existence of the bearing plates between the bridge pier and the superstructure which make seismic dissipation till failure. It is also noted that the superstructure of the continuous bridge shifted $50 \mathrm{~mm}$. Fig. 18 \& 19 shows the principal strain of models C-B-2 and M-B-2. It is noticed that the cracks existed at the pier bases in C-B-2. While in the monolithic bridge model, due to the rigid connection between the bridge piers and the bridge superstructure, it is noted that increased cracks existed at both ends of the bridge piers and the cracks are extended to the upper surface of the bridge superstructure.

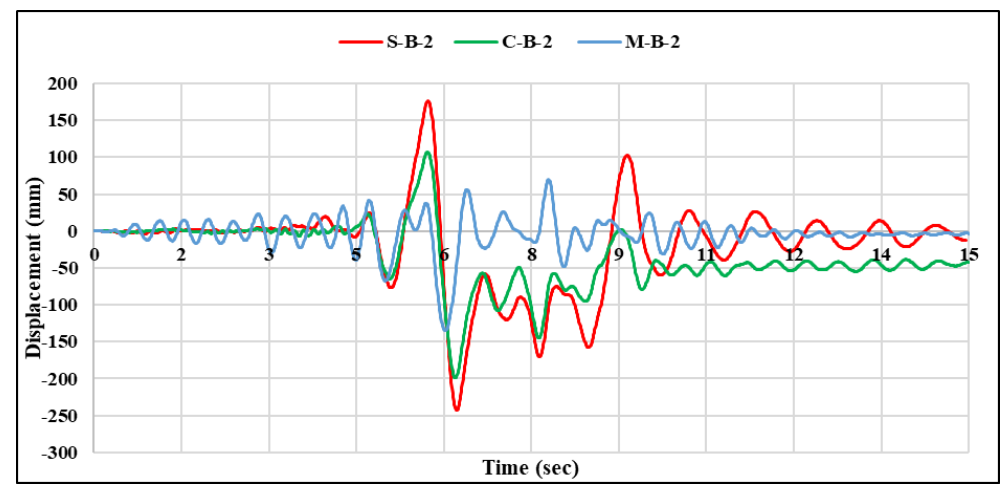

Figure 17 Displacement-Time History of the Middle Pier of Models S-B-2, C-B-2, and M-B-2
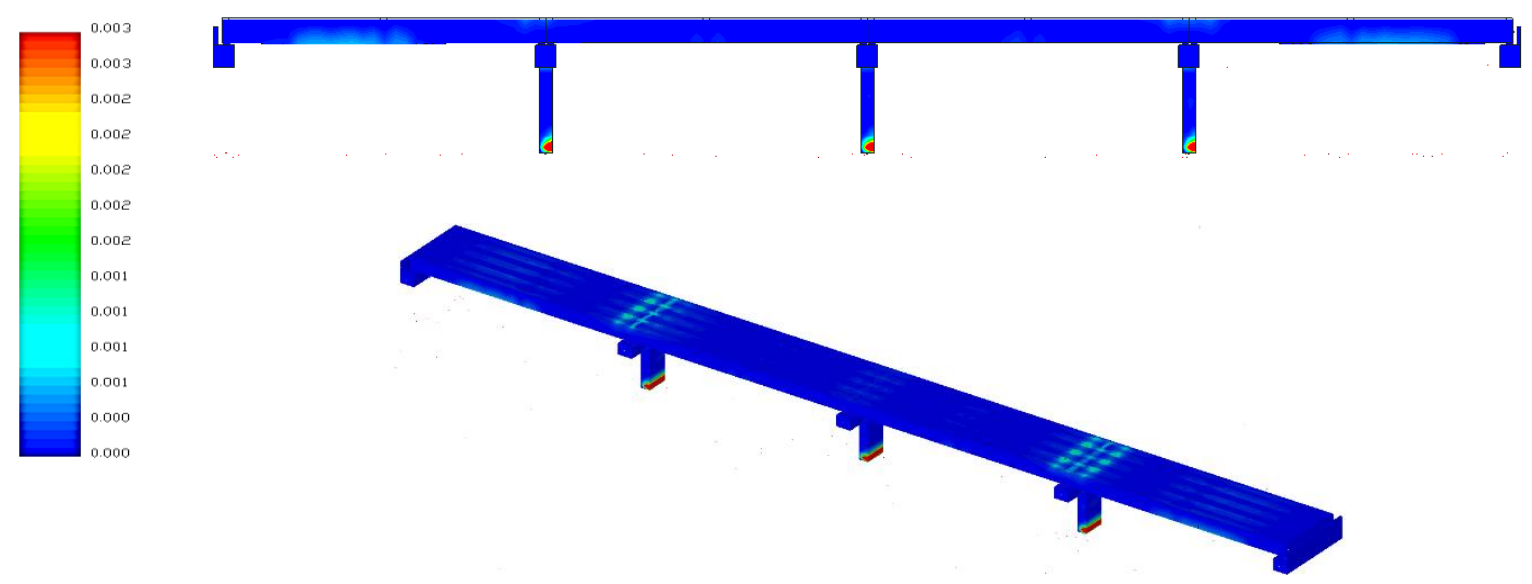

Figure 18 Displacement-Time History of the Middle Pier of Models S-B-2, C-B-2, and M-B-2 


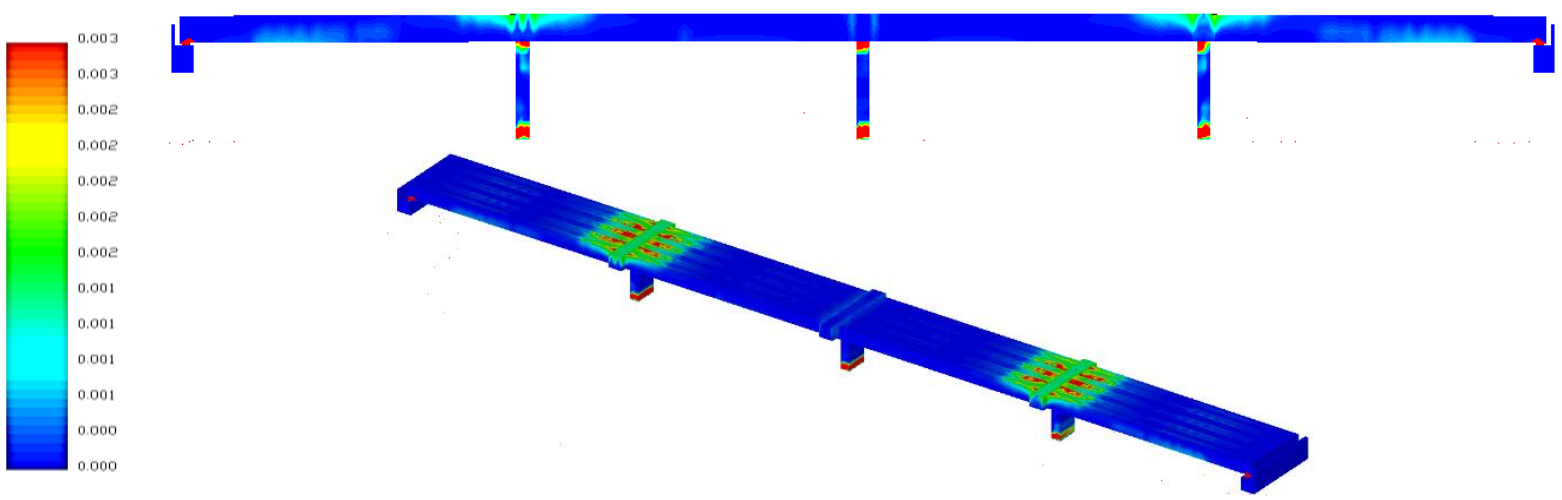

Figure 19 Displacement-Time History of the Middle Pier of Models S-B-2, C-B-2, and M-B-2

Fig.20, shows the Time History of models S-B-2, C-B-2, and M-B-2 respectively it will be noted that in simple and continuous on bearing bridge configurations, the time history is more uniform and the pier is less affected by the seismic ground motion as a result of the existence of the bearing interface between the bridge superstructure and the piers. On the other hand, the monolithic with Columns Bridge model, M-B-2, is strongly affected by the seismic ground motion as a result of nonexistence of the bearing interface.

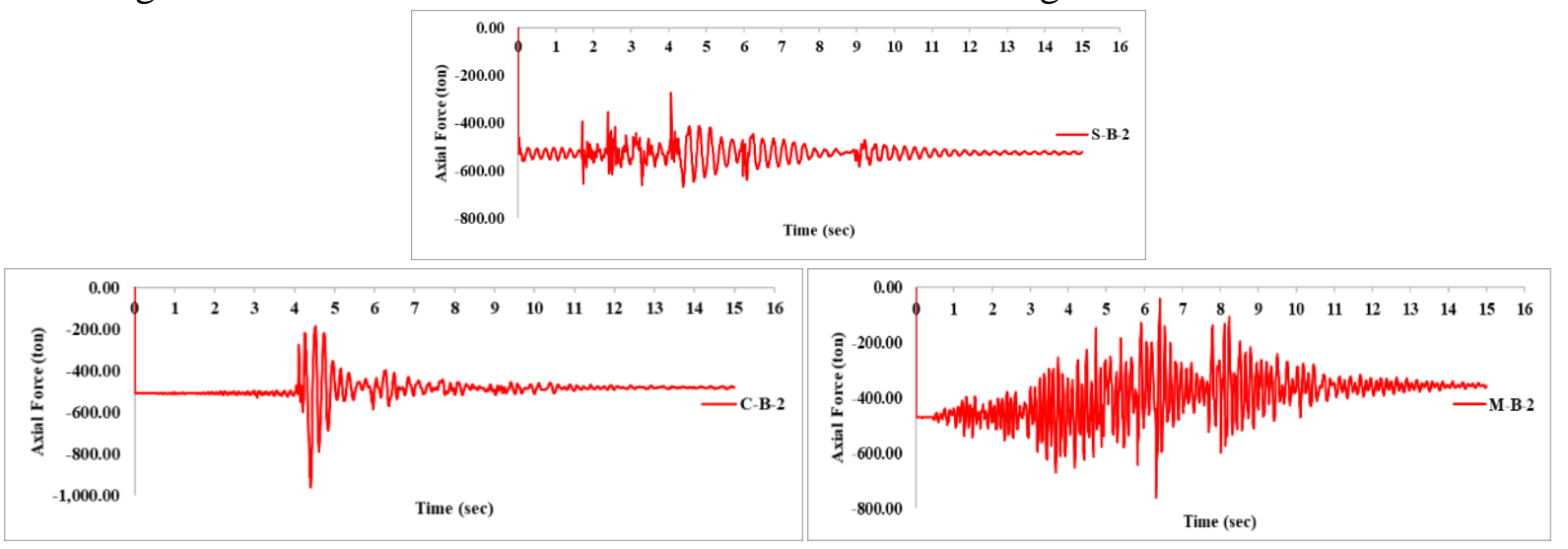

Figure 20 Axial Force-Time History: (a) S-B-2; (b) C-B-2; and (c) M-B-2

\section{CONCLUSION}

- Using the bridge bearings with low shear modulus can dissipate the seismic energy and act as vibration isolator between the bridge piers and the superstructure.

- By increasing the shear modulus with a significant values, the bridge substructure and superstructure will have the same resonance wave and the same amplitude and will increase the base shear on the piers and will increase the cracks near the base. On the other hand, it will reduce the maximum displacement amplitude of the bridge substructure during the time history analysis.

- The monolithic bridge models shows a less displacement amplitudes when compared with to continuous, and simple on bearing bridge models but it has more excessive cracks than simple and continuous on bearing bridge models.

- One of the most important notes is that extreme seismic ground motions has a low effect on actually RC bridge structures that is executed in Egypt according to the Egyptian code of practice.

- The behavior RC bridge structures can be modeled and analyzed efficiently using ELS via AEM. 


\section{REFERENCES}

[1] AASHTO, 2002. Standard Specifications for Highway Bridges, Seventeenth Edition, American Association of State Highway and Transportation Officials.

[2] ECP: ECP-203: Egyptian code for design and construction of RC structures, ECPCS-203. Housing and Building National Research Center. Ministry of Housing, Utilities and Urban Planning, Cairo; 1989.

[3] Yazdani, N., Eddy, S., Cai, C.S., 2000.Effect of Bearings on Precast Pre-stressed Concrete Bridges, Journal of Bridge Engineering, 5(3), 224-232.

[4] Jangid, R.S., 2002. Seismic Response of Bridges, Journal of Engineering, 9(2), 156-166.

[5] Dicleli, M. and Buddaram, S., 2006. Equivalent linear analysis of seismic-isolated bridges subjected to near fault ground motions with forward rupture directivity effect, Elsevier.

[6] Dai, W., Moroni, M.O., Roesset, J.M., Sarrazin, M., 2005. Effect of isolation pads and their stiffness on the dynamic characteristics of bridges, Elsevier.

[7] Kikuchi M. and Aiken, I.D., 1996. An Analytical Hysteresis Model for Elastomeric Seismic Isolation Bearings, Earthquake Engineering and Structural Dynamics, Vol.26, 215-231.

[8] ASI (Applied Science International). (2018). Extreme loading for structures 3.1. 〈http://www.appliedscienceint.com/extreme-loading-forstructures/〉 (May 10, 2018).

[9] Tagel-Din, H., and Meguro, K. (2000a). Applied element method for dynamic large deformation analysis of structures. Struct. Eng. Earthquake Eng., 17(2), 215-224.

[10] Tagel-Din, H., and Meguro, K. (2000b). Applied element method for simulation of nonlinear materials: Theory and application for RC structures. Struct. Eng. Earthquake Eng., 17(2), 123s-148s.

[11] Bathe, K. (1995). Solution of equilibrium equations in dynamic analysis, Prentice Hall, Englewoods Cliffs, NJ.

[12] Chopra, A. (1995). Dynamics of structures: Theory and applications to earthquake engineering, Prentice Hall, Englewoods Cliffs, NJ.

[13] Maekawa, K., and Okamura, H. (1983). The deformational behavior and constitutive equation of concrete using the elastoplastic and fracture model. J. Faculty Eng. Univ. Tokyo (B), 37(2), 253-328.

[14] Salem, H., Mohssen, S., Nishikiori, Y., \& Hosoda, A. (2016). Numerical Collapse Analysis of Tsuyagawa Bridge Damaged by Tohoku Tsunami. Journal of Performance of Constructed Facilities, 30(6), 04016065. DOI:10.1061/(ASCE)cf.1943-5509.0000925.

[15] Akogul, C., and Celik, O. (2008). "Effect of Elastomeric Bearing Modeling Parameters on The Seismic Design of Rc Highway Bridges With Precast Concrete Girders"

[16] Ngawest2.berkeley.edu. (2020). PEER Ground Motion Database - PEER Center. [online] Available at:https://ngawest2.berkeley.edu/spectras/191246/searches/176626/edit [Accessed 17 Jan. 2019].

[17] Chen, W.-F., \& Duan, L. (2014). Bridge engineering handbook. Boca Raton: CRC Press, Taylor \& Francis Group.

[18] Aria, M., \& Akbari, R. (2013). Inspection, condition evaluation, and replacement of elastomeric bearings in road bridges. Structure and Infrastructure Engineering, 9(9), 918-934. 